\title{
Seeking, sometimes finding, that elusive chemistry
}

\author{
Despite all the discipline's achievements, opinion is divided as to whether chemistry is \\ getting the recognition it deserves — and needs - in order to keep attracting new talent.
}

Sir — The Opinion article "A discipline buried by success" (Nature 411, 399; 2001) and News Feature "What's in a name?" (Nature 411, 408-409; 2001) in the 24 May issue are correct in their analysis of the lack of recognition of chemistry, in and outside the international scientific community. Scientists, policy-makers and the general public should take note of these timely messages.

I would like to add that the lack of recognition for the breadth of modern chemistry in China is hurting chemistry and related fields.

On 12 May 2001, the Nobel laureate Harry Kroto delivered a lecture titled "Science: a round peg in a square world", at the Great Hall of the People at Beijing, in which he passionately called for both better understanding of the role of basic research and better public understanding of scientific ideas. I was delighted to serve as Professor Kroto's translator, and accompanied him to a discussion with 50 high-school students at No. 4 High School in Beijing, one of China's few élite schools.

One student asked why, with biology in the ascendant, she should study chemistry. Part of Kroto's answer was that understanding and controlling chemistry at the molecular level is the key to the success of molecular biology and molecular electronics. This information was new to these bright young students, who will soon be choosing their careers.

In China, the lack of recognition of the breadth of chemistry is alarming. Biochemistry, for example, has never been a discipline within chemistry. The Chinese Chemical Society (CCS) does not have a biochemistry division, and the chemistry division of the National Natural Science Foundation does not support biochemistry research. The recent hype about state projects on the human genome sequence and related fields (Nature 410, 10-12; 2001) excludes the involvement of chemists. The president of the American Chemical Society told me in Beijing that more than $50 \%$ of the society's members are industrial chemists: in contrast, there is not even a Chinese word for 'industrial chemists'. China does have 'chemical engineers', but they are not covered by CCS membership.

Modern chemistry is about much more than beakers and flasks. The discoveries of buckminsterfullerene $\left(\mathrm{C}_{60}\right)$ and carbon nanotubes have reminded us that chemical synthesis can be done with sophisticated machines. The widely used technique of electrospray mass spectrometry in medical screening and biological analysis was developed and perfected in physical chemistry laboratories.

Yet the Chinese science community and China's educational administrators have failed to recognize many of these facts which is largely why the country's undergraduate and graduate chemistry programmes are outdated.

One of the direct consequences is that my laboratory cannot find students with decent training in modern physical chemistry.

Graduate students and postdocs from China have become a sizeable part of the research force in many US and European research institutions, so China's lack of modern chemistry skills is also a loss to the world at large.

Hong-fei Wang

State Key Laboratory of Molecular Reaction Dynamics (Beijing), Centre for Molecular Sciences, Institute of Chemistry, Chinese Academy of Sciences, No. 2, 1st North Street, Zhongguancun, Haidian District, Beijing 100080, China

\section{Researchers are popular, even if the industry is not}

Sir - Your disappointing Opinion article and News Feature (Nature 411, 399 and 408-409; 2001), bemoaning the poor public image of chemists and chemistry, do not refer to a recent survey carried out by Wirthlin Worldwide and sponsored by the American Chemical Society (see http://www. acs.org/wirthlin.html). This research indicates that the US public views chemists favourably in many ways, associating them with being visionary, innovative and results-oriented.

Although concerned about the effects of chemicals on their everyday health and safety, respondents also had positive feelings about a range of chemistry's contributions to everyday life, from agriculture to cleaning products. And although your articles suggest that chemistry achievements such as new pharmaceuticals are "being appropriated by other disciplines", more respondents to our survey credited chemists with that achievement than with any other.

Nearly 18,000 international scientists attended the ACS meeting that was featured in your Opinion article, not 1,000 , as Nature reported.

\section{Denise Graveline}

American Chemical Society, 1155 16th Street NW, Washington, DC 20036, USA

We apologize for the inadvertent error in our reporting of the number of scientists at the meeting, which was introduced during editing - Correspondence Editor, Nature.

\section{Time to shout about the benefits of chemistry}

Sir - In your interesting Opinion article on chemistry (Nature 411,399; 2001), you comment that in my Perspective article

"The Quiet Revolution in

Chemistry"(Chemical and Engineering

News 64-65, 7 August 2000), I stop short of identifying potential applications. This is not so.

In my Perspective I identify how, by achieving one or more of the objectives on my 'wish list', chemists could contribute significantly to improving the human condition.

I list three of many possible applications in an 'imagine' list: imagine bridges that do not corrode; imagine Rome, Bangkok and Los Angeles with no air pollution, and with tap water that you would enjoy drinking; and imagine learning the entire health profile of a person from a drop of blood.

My point was to highlight some of the grand challenges of fundamental chemistry, which many believe are as exciting and important as similar challenges in our sister fields of biology and physics.

I used the term "quiet" in the sense that the science media are not fully aware of these revolutionary objectives, and Nature is to be applauded for helping to make the revolution more noisy.

Stephen J. Lippard

Department of Chemistry, Massachusetts

Institute of Technology, Cambridge,

Massachusetts 02139, USA 


\section{Singapore makes efforts to sustain biodiversity}

Sir-Agoramoorthy and Hsu in Correspondence (Nature 410, 144; 2001) express the fear that, although Singapore is creating a genome project costing S\$62 million (US\$35 million) over five years, it is ignoring some serious environmental issues.

They suggest that the number of future students of ecology and conservation in Singapore may fall, and rightly point out that, as an economic giant, Singapore has the responsibility to care for its natural environment and to help to conserve natural resources in neighbouring 'mega-diversity' countries.

They mention the government's conservation fund and Wildlife Reserves Singapore. These are not, however, the only large and long-standing conservation efforts under way. For example, the National University of Singapore (NUS) has been very active in conservation work and biodiversity research for some 30 years. In 1998, the Raffles Museum for Biodiversity Research was established at the NUS, with a budget of about $S \$ 2.7$ million, specifically to promote research on biodiversity and to deal with conservation issues in collaboration with the Singapore National Parks Board. These institutions have hosted hundreds of researchers from many countries who study biodiversity in Southeast Asia.

Between 1994 and 1999, NUS staff and students published some 300 articles, many in the leading scientific journals of their fields (Ng, P. K. L. National Science Museum Monographs (Tokyo) 18,2-23;2000). The NUS itself publishes the Raffles Bulletin of Zoology, an international, peer-reviewed journal of faunal studies in Southeast Asia. The Raffles Museum for Biodiversity Research has been involved in joint research and training projects with neighbouring countries, notably Brunei, China, Indonesia, Malaysia, the Philippines, Sri Lanka, Taiwan, Thailand and Vietnam. Further, a new public exhibit gallery aimed at promoting public awareness and education in conservation opened on 15 June 2001 (see http:// www.rmbr. nus.edu.sg).

We have been impressed by the enthusiasm of numerous graduate students dedicated to ecology, biodiversity and conservation research at the NUS.

Contrary to the fears of your

correspondents, much emphasis has been placed on such issues at the NUS over the past decade and we think that Singapore is well equipped to tackle them.

We hope that the government of Singapore will continue its commitment to and funding of biodiversity research and conservation in this rich island nation. Lanna Cheng*, Damir Kovac $\dagger$

${ }^{*}$ Scripps Institution of Oceanography, University of California, San Diego, La Jolla, California 92093-0202, USA

†Forschungsinstitut Senckenberg, Senckenberganlage 25, 60325 Frankfurt am Main, Germany

\section{Photos may offer clues over Ethiopian fossil site}

Sir - Horst Seidler, in his Correspondence (Nature 411, 15; 2001) responding to the News story "Restrictions delay fossil hunts in Ethiopia” (Nature 410, 728; 2001), states that his use of the Galili research site in Ethiopia is legal. But I, not he, discovered this site, as shown in the accompanying photograph.

The Ethiopian Authority for Research and Conservation of Cultural Heritage, which regulates the use of sites, incorrectly assumed that Galili and the Mulu Basin are different, and has been persuaded to allow Seidler's occupation to continue.

After participating in the discovery of Galili in 1997, I worked there each year under official permit. Then, after my first publication from this site (Am. J. Phys. Anthrop. 111, Suppl. 30, 170; 2000), Seidler arrived there, camping less than 200 metres from the place where I had found hominid fossils two years earlier. Now he claims, incorrectly, that my permit was for a different area, although the photographs below clearly show his camp in the same area as my earlier site.

Seidler notes that after arriving at my site, he offered to let me join his team. This

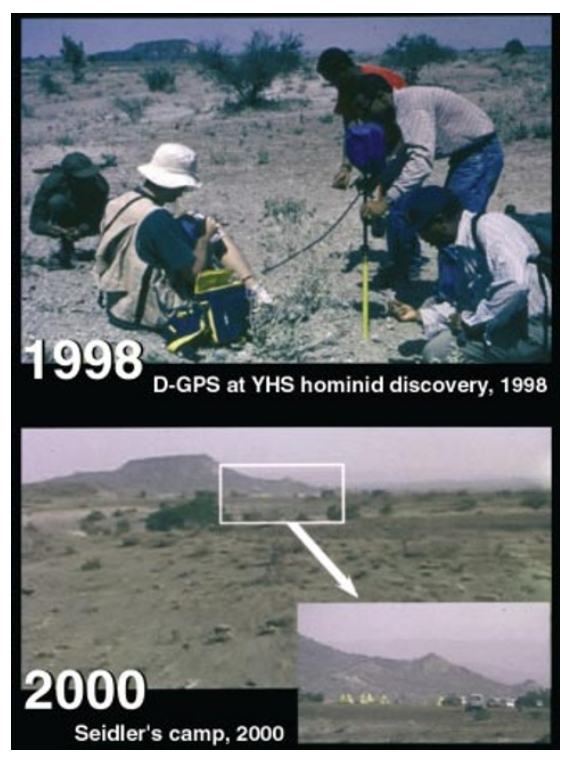

Digging in: Haile-Selassie's Galili camp, top, and Seidler's camp, bottom and inset. offer was completely inappropriate as the site was mine in the first place. It would have been far better for Professor Seidler to have withdrawn from Galili when I appealed to Ethiopian regulators about his team's arrival there. Instead, he first apologized for what happened, now claims that my permit was for a different area, and continues to occupy the site.

Yohannes Haile-Selassie

Laboratory for Human Evolutionary Studies, Department of Integrative Biology, University of California, Berkeley, California 94720, USA

\section{Keeping Mendel in mind}

Sir-Science is a function of cultural and social imprinting, the impression left by the environment in which a researcher lives and works. Johann Gregor Mendel lived in difficult circumstances, with his work neglected during his lifetime, and disregarded under the influence of Trofim Lysenko. Now, as your News story "Museum suffers spiritual cramps over Mendel's work" (Nature 410, 6; 2001) makes clear, the Mendel museum in Brno, the Mendelianum, is under threat on rather flimsy religious grounds.

After a recent international human genetics meeting in Vienna, I visited the the Mendelianum and the abbey where Mendel designed and performed the experiments forming the cornerstone of genetics. The museum is managed by cordial, enthusiastic people, but it is small and has limited resources compared with similar institutions in Eastern Europe, for example the museum dedicated to Ignaz Semmelweis in Budapest. Few of my colleagues at the Vienna meeting were interested in visiting the cradle of genetics, and there is an air of indifference in this lovely city towards such an illustrious citizen and his memorial.

Given the relevance and impact of genetics, most recently with the decoding of the human genome sequence, the scientific community, especially in Eastern Europe, must support the Mendelianum. A fund could be established, genetics meetings could be held in Brno, and promotional material could be distributed to research centres, museums and other institutions across the world. Hence, future generations will become culturally 'imprinted', not with the dogmatic ignorance of Lysenko's heirs, but with the work of this universal figure to whom we, as a rational species, owe so much.

\section{Fabio Salamanca}

Unit of Medical Research in Human Genetics, National Medical Center, Mexican Institute of Social Security, Apartado postal 12-951, Mexico DF 03020, Mexico 